\title{
Thermal Profile of Pulse Precision Capsulotomy: In Vivo and In Vitro Infrared Thermography Study
}

\author{
Jae-Hong An, Jong-Hwa Jun \\ Department of Ophthalmology, Keimyung University School of Medicine, Daegu, Korea
}

\begin{abstract}
Purpose: This study aimed to elucidate the thermal safety of precision pulse capsulotomy (PPC) via in vivo and in vitro evaluation of the thermal profile using infrared thermography.

Methods: This prospective observational study enrolled 15 eyes from 15 participants who underwent cataract surgery using the Zepto PPC. All patients underwent temperature measurements of the incision site and the entire cornea using an infrared thermographer during the capsulotomy procedure. To accurately analyze the temperature change of the Zepto PPC, infrared thermography was performed with the Zepto handpiece while exposed to air and then in porcine eyes. Moreover, in each case, the difference in temperature change according to the use of an ophthalmic viscosurgical device (OVD) was also checked to determine the temperature buffering effect.
\end{abstract}

Results: In the clinical evaluations, the mean temperature elevation around the corneal incision and time duration from baseline to peak temperature during the Zepto capsulotomy were $4.0^{\circ} \mathrm{C} \pm 1.9^{\circ} \mathrm{C}$ and $4.43 \pm 1.26$ seconds, respectively, with a mean peak temperature of $32.6^{\circ} \mathrm{C} \pm 2.0^{\circ} \mathrm{C}$. The mean peak temperature and rise time of the naïve Zepto nitinol ring, as measured from the bottom side, were $109.0^{\circ} \mathrm{C} \pm 22.9^{\circ} \mathrm{C}$ and $43.40 \pm 11.06$ seconds in the experimental procedures, respectively. In the porcine eyes, the mean elevation of temperature and rise time of the Zepto nitinol ring were $6.2^{\circ} \mathrm{C} \pm 1.6^{\circ} \mathrm{C}$ and $11.67 \pm$ 2.08 seconds with the use of OVDs, and $10.5^{\circ} \mathrm{C} \pm 3.3^{\circ} \mathrm{C}$ and $14.00 \pm 3.61$ seconds without OVDs, respectively.

Conclusions: Zepto PPC has the potential to generate extremely high thermal energy, according to an in vitro study. However, the temperature rise of the Zepto capsulotomy can be minimized by using OVDs.

Key Words: Infrared capsulotomy, Precision pulse capsulotomy, Temperature profile, Thermal capsulotomy

Among the conventional steps for cataract surgery, continuous curvilinear capsulotomy is an important procedure that can influence subsequent steps such as hydrodissec-

Received: May 23, 2021 Final revision: August 6, 2021

Accepted: August 6, 2021

Corresponding Author: Jong Hwa Jun, MD, PhD. Department of Ophthalmology, Keimyung University School of Medicine, 1035 Dalgubeol-daero, Dalseo-gu, Daegu 42601, Korea. Tel: 82-53-258-4545, Fax: 8253-258-7130, E-mail: junjonghwa@gmail.com tion, phacoemulsification of the lens, and insertion of the intraocular lens (IOL) [1]. Precise and proper size of capsulotomy is crucial; this is because small capsulorhexis results in excessive anterior capsular fibrosis, regarded as residual lens epithelial cells [2], which could move the IOL backward to induce hyperopia $[3,4]$. Conversely, a large capsulorhexis can lead to IOL tilting, decentration, and early posterior capsule opacification [5-7].

In fact, it is impossible to manually create a uniform capsulotomy of the same shape and size. However, femtosec- 
ond laser-assisted cataract surgery (FLACS) can compensate for this shortcoming. FLACS can produce consistent and accurate anterior capsulotomy with high reproducibility and predictability [8-12]. Consistent and identical anterior capsulotomy can guarantee the precise positioning of the IOL [10]. However, FLACS requires numerous equipment, high procedure costs, longer operating times, and additional space. Additionally, it may be difficult to perform femtosecond laser procedures in patients with poor mydriasis or corneal opacity [13].

The recently introduced precision pulse capsulotomy (PPC) (Zepto; Mynosys, Fremont, CA, USA) is a semi-automated alternative to conventional capsulotomy. Using 12 micropulses of energy in 4-ms intervals, PPC can instantly create a circular anterior capsulotomy with an average diameter of $5.2 \mathrm{~mm}$ [14]. In addition to our previous study [15], recent studies demonstrated that this thermal capsulotomy device produces consistent and reproducible symmetric capsulotomies [16-19]. According to the manufacturer, the temperature rise during thermal capsulotomy using Zepto PPC is not significant enough to damage the eyes, but no experimental or clinical studies confirming the heat generation by Zepto have been reported. Furthermore, in terms of devices that are based on heat generation, there is a possibility that they may cause serious damage to the intraocular tissues such as the endothelium or iris, as well as long-term complications due to capsular contraction. In this study, we aimed to elucidate the thermal safety of Zepto PPC by performing in vivo and in vitro evaluations of the thermal profile using infrared thermography during thermal capsulotomy.

\section{Materials and Methods}

\section{Patients}

Of the patients scheduled for cataract surgery, we enrolled 15 patients ( 15 eyes) who underwent cataract surgery in this prospective observational study from May 2018 to October 2018. Seven eyes on the right and eight eyes on the left were included from seven male and eight female patients. The research was performed at the department of ophthalmology, Dongsan Medical Center, affiliated with Keimyung University in Daegu, Korea. All clinical evaluations and measurements followed the tenets of the Declaration of Helsinki, and the research protocol was reviewed and approved by the Ethics Committee of Dongsan Medical Center (DSMC 201807-007). Informed consent was obtained from all patients after describing the details of the study. The inclusion criteria were age-related cataracts with favorable physical status and uneventful in-the-bag IOL implantations of one of both eyes. Those with a previous history of intraocular surgery, previous ocular trauma or uveitis, an axial length shorter than $22.0 \mathrm{~mm}$ or longer than $24.5 \mathrm{~mm}$, pseudoexfoliation syndrome, poor pupil dilation, preoperative or perioperative zonular weakening were excluded.

\section{Measurements}

Ophthalmologic examinations included several parameters. The preoperative values were axial length and anterior chamber depth acquired using optical low-coherence reflectometry (Lenstar LS900; Haag-Streit AG, Bern, Switzerland). Cataract nuclear opalescence was graded from 1 to 5 according to the Lens Opacity Classification System III criteria [20]. Preoperative and 1-day postoperative values included uncorrected visual acuity (UCVA), best-corrected visual acuity (BCVA) recorded in logarithm of the minimum angle of resolution units, spherical equivalent performed by autorefraction (RK-F2; Canon, Tokyo, Japan), and intraocular pressure (IOP) measured using a non-contact tonometer (NT-530P; Nidek, Tokyo, Japan).

\section{Surgical procedures}

Approximately 1 hour before surgery, each patient was twice-instilled with $0.5 \%$ tropicamide $/ 0.5 \%$ phenylephrine fixed combination eye drops (Tropherine; Hanmi Pharm, Seoul, Korea) for 5 minutes in order to maximize pupil dilation. All surgeries were performed by the same surgeon (JHJ), who performed a 2.85 coaxial incision (Infiniti Vision System; Alcon, Fort Worth, TX, USA). After instillation of $0.5 \%$ proparacaine topical anesthetic eye drops (Paracaine, Hanmi Pharm), a clear corneal incision was made at the 9 o'clock (right eye) and 2 o'clock (left eye) positions. Before anterior capsulotomy, a viscoelastic device (DisCoVisc, Alcon) was placed in the anterior chamber through a sideport incision at the 12 o' clock position (right eye) and 5 o' clock position (left eye). During the capsulotomy procedure, we performed corneal marking using a $5.5-\mathrm{mm}$ capsulotomy marker. The PPC device's nitinol cutting ele- 
A

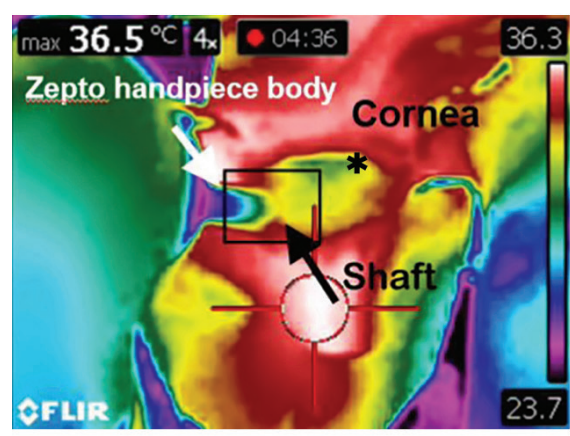

C

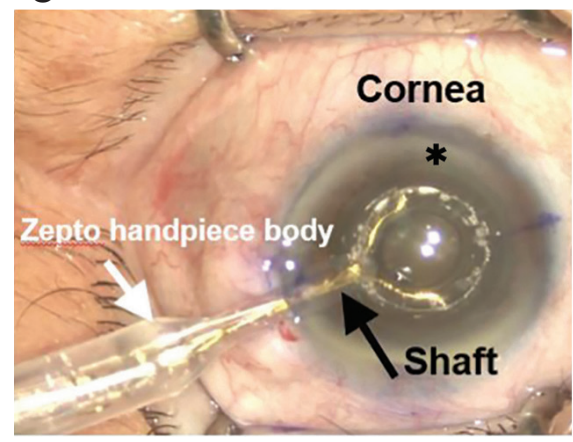

B

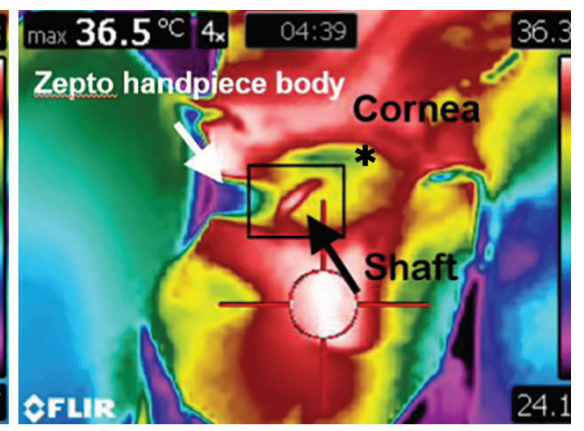

D

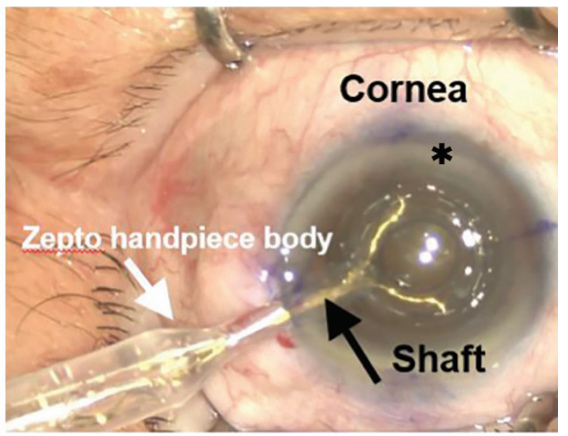

Fig. 1. Infrared thermography performed on patients enrolled in this study. During Zepto (Mynosys, Fremont, CA, USA) capsulotomy, an infrared thermographer was focused on the corneal incision site and Zepto handpiece shaft. (A-D) Additionally, the handpiece shaft (black arrow) temperature can be compared by color with the cornea (black asterisk) and the Zepto handpiece body (white arrow). (A) Infrared thermography did not show any specific temperature changes before performing the capsulotomy procedure (precut). (B) During the capsulotomy cutting procedure, it was observed that thermal energy was transferred from the shaft of the handpiece to the nitinol ring (cut). (C) Real images of the surgery before the cutting procedure (precut). (D) Real images of the surgery during the cutting procedure (cut). Informed consent for publication of the clinical images was obtained from the patient. ment was inserted into the anterior chamber through the corneal incision and positioned centrally on the anterior capsule under the corneal marking. An assistant then applied suction to allow for the apposition of the nitinol ring with the capsule. After adequate suction was completed, the cutting procedure was performed, as indicated by the console, and the electrical energy was released. After the introduction of the Zepto PPC handpiece, the thermal profile of the corneal incision site adjacent to the Zepto PPC shaft was recorded using an infrared thermographer (T420bx; Flir Systems, Wilsonville, OR, USA) with a temperature range of $-20^{\circ} \mathrm{C}$ to $350^{\circ} \mathrm{C}$ and thermal sensitivity of $0.04^{\circ} \mathrm{C}$ (Fig. 1A-1D). All thermographic profiles were recorded as sequence files on a connected laptop computer and analyzed using the Flir tool + (Flir Systems). To easily rotate the lens nucleus, hydrodissection was conducted, and phaco-chop was performed to emulsify and remove the nucleus. After removal of the remaining cortex material, insertion of the hydrophobic one-piece IOL (AcrySof IQ SN60WF, Alcon), and aspiration of the ophthalmic viscosurgical device (OVD), the corneal wound was hydrated. Patients were treated with $0.5 \%$ moxifloxacin eye drops (Vigamox, Alcon) and a 1\% prednisolone acetate ophthal- mic suspension (PredForte; Allergan, Irvine, CA, USA) four times a day after surgery for more than 3 weeks.

\section{In vitro experimental procedures}

Porcine eyes were obtained from a slaughterhouse approximately 3 to 5 hours after death. An in vitro study was carried out to record temperature using three conditions: (1) with the Zepto PPC nitinol ring positioned naïvely in open air or on the porcine lens surface, (2) with, or (3) without an OVD. During the procedures, the thermal profile was recorded by directly targeting the ring using a compact infrared thermographer (Flir C2, Flir Systems) with a temperature range of $-10^{\circ} \mathrm{C}$ to $150^{\circ} \mathrm{C}$ and a thermal sensitivity of $0.1^{\circ} \mathrm{C}$. All thermographic profiles were recorded and analyzed using the Flir tool +. To check the naïve temperature, the Zepto PPC handle was fixed using silk tape on the floor with nothing around the Zepto PPC nitinol ring, and the thermal profile was acquired during the suction and cutting procedures in the top, lateral, and bottom views. To keep the measurement conditions similar to the in vivo experiment in which the OVD could be placed in the anterior chamber, the porcine cornea was resected above the limbus 
in a dome shape. The lenticular surface was coated with a DiscoVisc OVD. The Zepto PPC nitinol ring was positioned at the center of the porcine lens surface. Suction was applied, and the cutting procedure was performed in the same manner as for the human eye (Fig. 2A-2C). To identify the possible heat damage to intraocular tissues such as the iris, endothelium, and corneal incision according to the presence or absence of the OVD, thermal profiles were obtained in the top and lateral views. However, the thermal profile of the bottom side was excluded because the Zepto nitinol ring directly contacted the lens capsule and tissues. Each experiment was repeated at least three times.

\section{Statistical analysis}

All temperature values were summarized as the means and standard deviations. Temperature changes and preoperative and postoperative parameters were compared using paired t-tests. Data were analyzed using IBM SPSS Statistics ver. 25.0 (IBM Corp., Armonk, NY, USA).

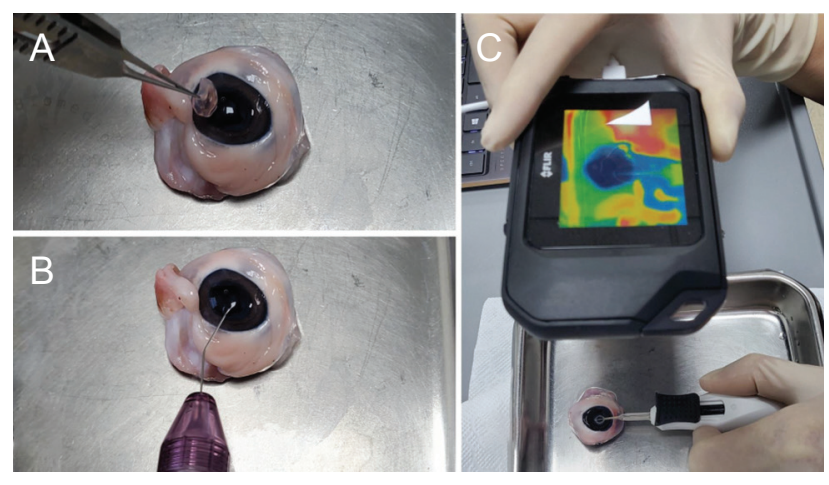

Fig. 2. Measurement method for thermal profile analysis of Zepto (Mynosys, Fremont, CA, USA) precision pulse capsulotomy using an infrared thermographer. (A) Since the infrared thermographer only measures the surface temperature, the porcine eye cornea was excised in a circular shape using scissors. (B) The lenticular surface was coated with a DiscoVisc (Alcon, Fort Worth, TX, USA) ophthalmic viscosurgical device. (C) The cutting ring of the Zepto precision pulse capsulotomy device was positioned at the center of the lens surface. Thermography was performed during the serial thermal capsulotomy procedure.

\section{Results}

\section{Patient demographics}

The mean age of the patients was $67.9 \pm 9.7$ years; nine patients $(60 \%)$ had hypertension and seven $(47 \%)$ had diabetes. The mean nuclear opalescence grade was $3.40 \pm 0.91$, and the mean axial length and anterior chamber depths were $22.92 \pm 0.77$ and $3.18 \pm 0.48 \mathrm{~mm}$, respectively. The mean preoperative UCVA and BCVA were $0.49 \pm 0.33$ and $0.42 \pm 0.34$, respectively, and the mean postoperative UCVA and BCVA were $0.22 \pm 0.17$ and $0.12 \pm 0.12$, respectively. The mean preoperative IOP was $12.9 \pm 1.8 \mathrm{mmHg}$ and the mean postoperative IOP was $15.1 \pm 3.9 \mathrm{mmHg}$. Both UCVA and BCVA improved significantly (difference: UCVA, $0.27 ; p=0.009$; BCVA, $0.30 ; p=0.003$ ).

\section{In vivo thermal profile}

During the cutting procedure, the mean time to peak temperature after the temperature rose around the corneal incision was identified to be $4.43 \pm 1.26$ seconds (range, 1.93-6.57 seconds). Baseline and peak temperature were $28.6^{\circ} \mathrm{C} \pm 1.7^{\circ} \mathrm{C}$ and $32.6^{\circ} \mathrm{C} \pm 2.0^{\circ} \mathrm{C}$ (range, $29.2^{\circ} \mathrm{C}-37.2^{\circ} \mathrm{C}$ ), respectively, which was insignificant (difference, $4.0^{\circ} \mathrm{C} \pm$ $1.9^{\circ} \mathrm{C} ; p=0.063$ ) (Fig. 3). The mean temperature rise

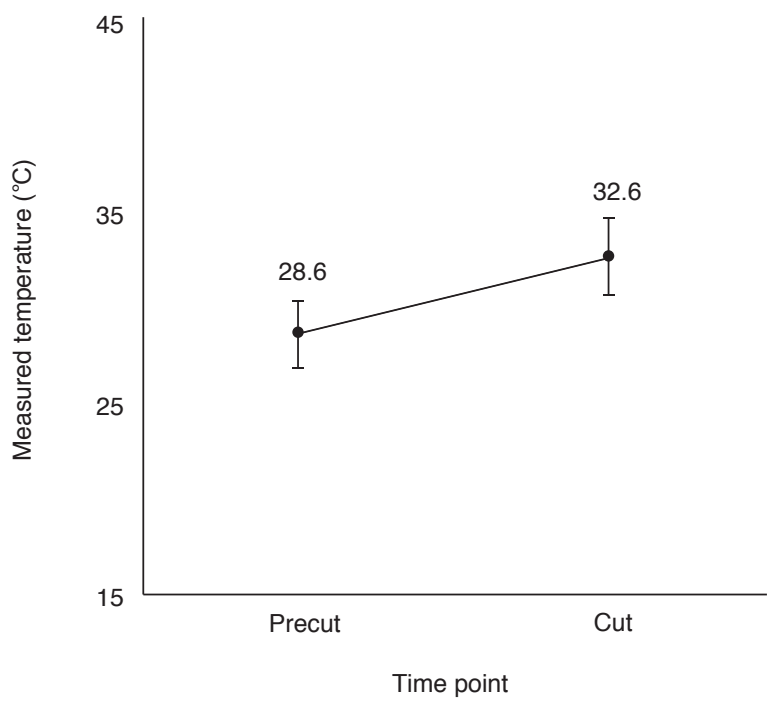

Fig. 3. The mean precut temperature was $28.6^{\circ} \mathrm{C} \pm 1.7^{\circ} \mathrm{C}$ and the mean peak temperature was $32.6^{\circ} \mathrm{C} \pm 2.0^{\circ} \mathrm{C}$ around the shaft and corneal incision. 
Table 1. Temperature profile of the corneal incision site in 15 patients who underwent Zepto capsulotomy during cataract surgery

\begin{tabular}{lcccc}
\hline $\begin{array}{c}\text { Patient } \\
\text { no. }\end{array}$ & $\begin{array}{c}\text { Baseline } \\
\text { temperature } \\
\left({ }^{\circ} \mathrm{C}\right)\end{array}$ & $\begin{array}{c}\text { Peak } \\
\text { temperature } \\
\left({ }^{\circ} \mathrm{C}\right)\end{array}$ & $\begin{array}{c}\text { Difference } \\
\left({ }^{\circ} \mathrm{C}\right)\end{array}$ & $\begin{array}{c}\text { Temperature } \\
\text { rise } \\
\text { duration } \\
(\mathrm{sec})\end{array}$ \\
\hline 1 & 29.8 & 30.7 & 0.9 & 3.56 \\
2 & 29.7 & 30.9 & 1.2 & 1.93 \\
3 & 28.7 & 30.8 & 2.1 & 6.30 \\
4 & 27.1 & 32.5 & 5.4 & 4.10 \\
5 & 32.6 & 34.2 & 1.6 & 4.50 \\
6 & 27.4 & 32.2 & 4.8 & 3.80 \\
7 & 26.2 & 31.4 & 5.2 & 3.41 \\
8 & 25.9 & 29.2 & 3.3 & 3.63 \\
9 & 27.7 & 31.6 & 3.9 & 3.36 \\
10 & 28.2 & 31.7 & 3.5 & 4.20 \\
11 & 30.1 & 34.7 & 4.6 & 5.80 \\
12 & 28.0 & 34.4 & 6.4 & 6.57 \\
13 & 29.1 & 32.9 & 3.8 & 5.49 \\
14 & 30.0 & 37.2 & 7.2 & 5.30 \\
15 & 28.2 & 34.0 & 5.8 & 4.46 \\
\hline
\end{tabular}

ranged from $0.9^{\circ} \mathrm{C}$ to $7.2^{\circ} \mathrm{C}$. The peak temperature was $>30^{\circ} \mathrm{C}$ in 14 of 15 cases. The in vivo thermal profiles are presented in Table 1.

\section{In vitro thermal profile}

The temperature elevation of the Zepto nitinol ring was highest on the bottom side (Fig. 4A) among the top (Fig. $4 \mathrm{~B})$, bottom, and lateral views in the naïve cutting procedures. The mean temperature rise time of the bottom view was identified as $43.40 \pm 11.06$ seconds, and the mean temperature rise was $79.9^{\circ} \mathrm{C} \pm 22.5^{\circ} \mathrm{C}$. The baseline and peak temperatures were $29.1{ }^{\circ} \mathrm{C} \pm 1.0^{\circ} \mathrm{C}$ and $109.0^{\circ} \mathrm{C} \pm 22.9^{\circ} \mathrm{C}$, respectively (Fig. 4A). In the top view, the baseline temperature was similar with the bottom view, but the peak temperature was measured only half from the bottom's value (Fig. 4B). When viewed through a thermographer, the temperature change of the Zepto shaft was significantly different depending on the presence or absence of the OVD in the lateral view. Without the OVD, the shaft's color change was easily detectable; however, with it, the shaft's color change was minimal and difficult to recognize (Fig. $4 \mathrm{C}, 4 \mathrm{D})$. In the top view, the mean temperature rise time was $14.00 \pm 3.61$ seconds, and the mean temperature rise was $10.5^{\circ} \mathrm{C} \pm 3.3^{\circ} \mathrm{C}$ without the OVD. The baseline and peak temperatures were $18.2^{\circ} \mathrm{C} \pm 0.1^{\circ} \mathrm{C}$ and $28.7^{\circ} \mathrm{C} \pm 3.4^{\circ} \mathrm{C}$, respectively (Fig. 5A). The mean temperature rise time of the Zepto nitinol ring with the OVD in the top view was $11.67 \pm 2.08$ seconds and the mean temperature rise was $6.2^{\circ} \mathrm{C} \pm 1.6^{\circ} \mathrm{C}$. The baseline and peak temperatures were $19.7^{\circ} \mathrm{C} \pm 0.8^{\circ} \mathrm{C}$ and $25.9^{\circ} \mathrm{C} \pm 2.3^{\circ} \mathrm{C}$, respectively (Fig. 5B).

\section{Discussion}

In the present study, we evaluated the temperature profiles of the Zepto PPC device in vivo and in vitro. Previous studies on the Zepto PPC showed that the device is as safe as conventional phacoemulsification cataract surgery with respect to complications such as corneal edema, anterior chamber inflammatory reaction, capsular fibrosis, anterior capsular opacity, posterior capsular opacity, and endothelial cell loss $[14,18,19]$. In our previous 59-case prospective study, we also verified the safety of PPC compared with conventional cataract surgery at 6 months follow-ups; there, we demonstrated less effective lens position variability and better circularity in the PPC group than in the continuous curvilinear capsulotomy group [15]. However, the aforementioned studies did not assess the temperature of the corneal incision site or anterior chamber during the cutting procedure during the clinical surgeries, which could potentially lead to overheat damage at the endothelium and anterior capsule cut edge.

According to a study of 20 live rabbit eyes, the Zepto PPC device can increase the anterior chamber temperature by approximately $1^{\circ} \mathrm{C}$ to $2^{\circ} \mathrm{C}$ in the eye (maximum, $2.01^{\circ} \mathrm{C}$ ) and return to the baseline temperature in 2 to 4 seconds (maximum, 4.60 seconds) [14]. In that particular study, the temperature was recorded using thermocouple temperature measurements, with probes placed in two locations in the anterior chamber adjacent to the suction cup and endothelium. However, our present study recorded general thermal profiles using an infrared thermographer; during the live human patient surgeries, the mean temperature elevation in the corneal incision site was $3.98^{\circ} \mathrm{C} \pm 1.91^{\circ} \mathrm{C}$, which was higher than $2.01{ }^{\circ} \mathrm{C}$. Moreover, in the in vitro study, the mean peak temperature in the naïve circumstance was elevated to $109.0^{\circ} \mathrm{C} \pm 22.9^{\circ} \mathrm{C}$ during the cutting procedure, in the bottom view, with no media around the Zepto nitinol 
A Bottom side measure

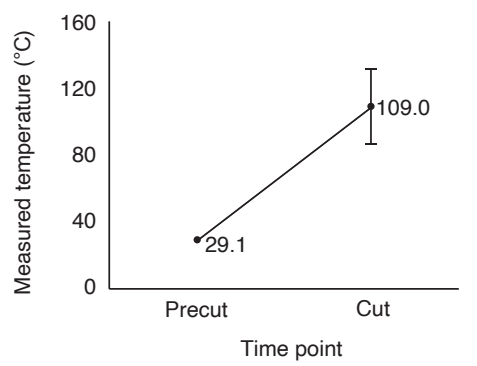

Temperature measure

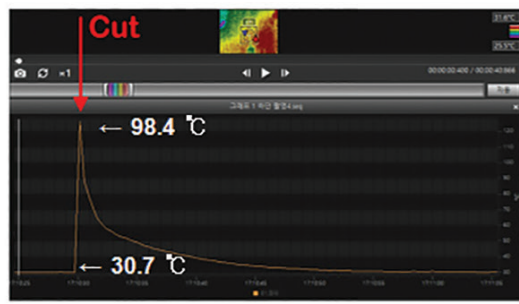

Temperature profile (cut)

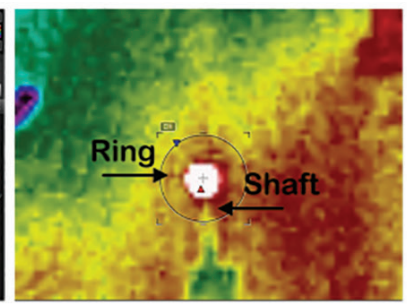

\section{B Top side measure}

Temperature measure

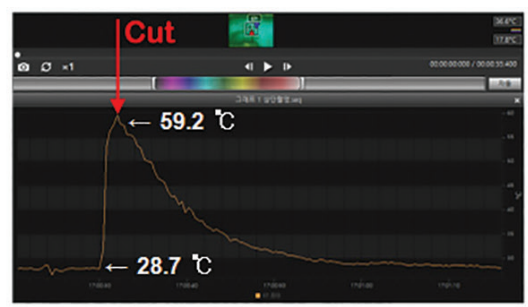

C Lateral side measure (OVD -)

\section{Temperature measure}

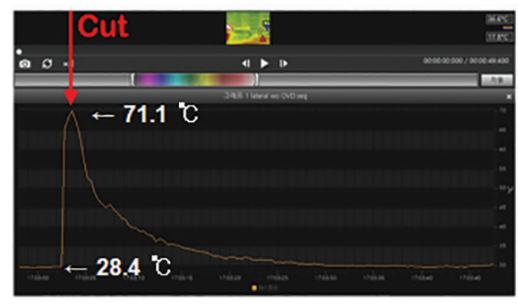

D Lateral side measure (OVD +)

Temperature measure

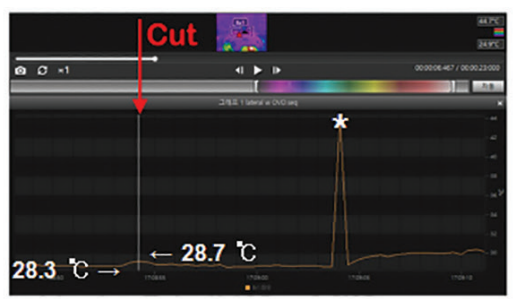

Temperature profile (precut)

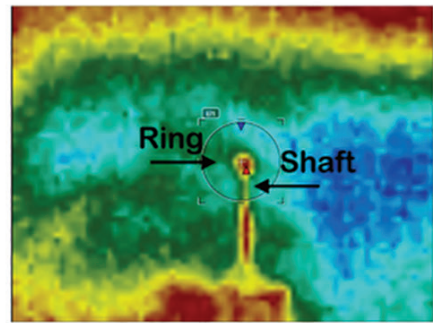

Temperature profile (cut)

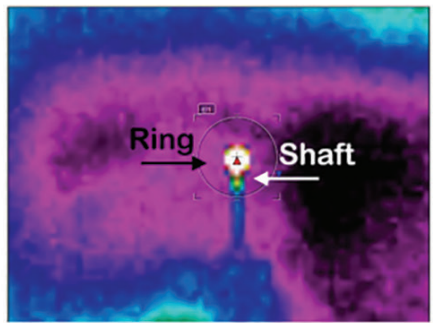

Temperature profile (precut)

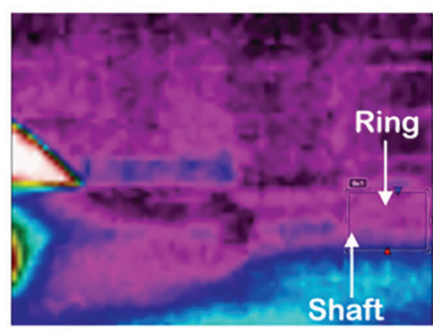

\section{Temperature profile (cut)}

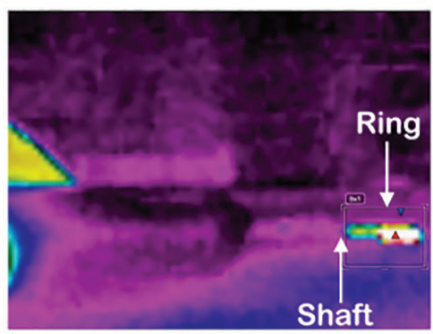

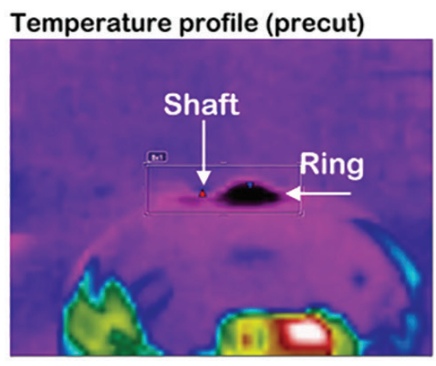

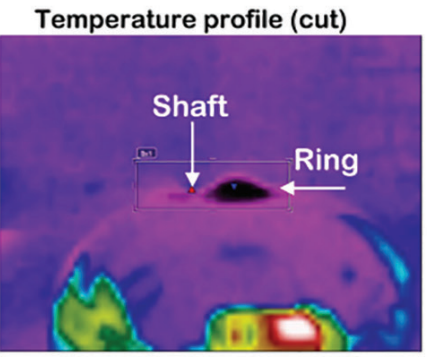

Fig. 4. The result of infrared thermography in three directions while performing thermal capsulotomy without contact with the porcine ocular tissue or the use of an ophthalmic viscosurgical device (OVD). (A) For the bottom side measurement, the mean peak temperature was $109.0^{\circ} \mathrm{C} \pm 22.9^{\circ} \mathrm{C}$ and was maintained for $43.4 \pm 11.06$ seconds. (B) For the top side measurement, the peak temperature $\left(59.2^{\circ} \mathrm{C}\right)$ was much lower than the bottom side measurement $\left(98.4^{\circ} \mathrm{C}\right)$. (C,D) The lateral side measurement with or without an OVD. (C) Without the OVD, slight elevation of temperature was observed but there was no change of temperature with the OVD. (D) A high temperature change (white asterisk) was detected, but this was due to an artifact caused by movement of the thermographer while measuring objects around the Zepto shaft. There was no temperature change detected apart from this error. 
A

\section{Pig eye crystalline lens surface (OVD-)}

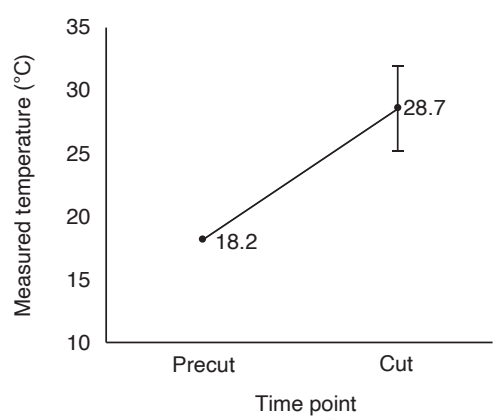

Temperature measure

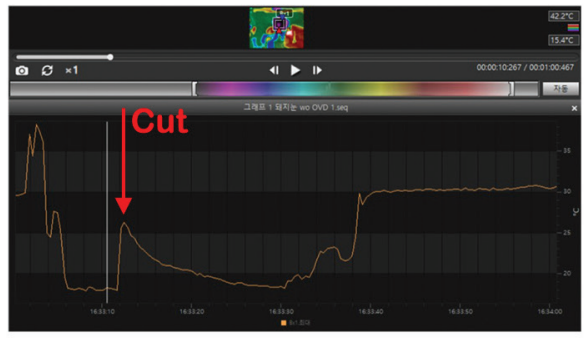

Temperature profile (cut)

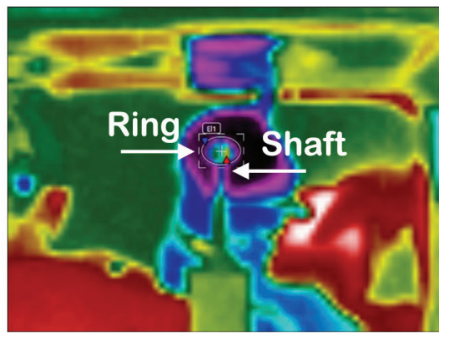

B Pig eye crystalline lens surface (OVD+)

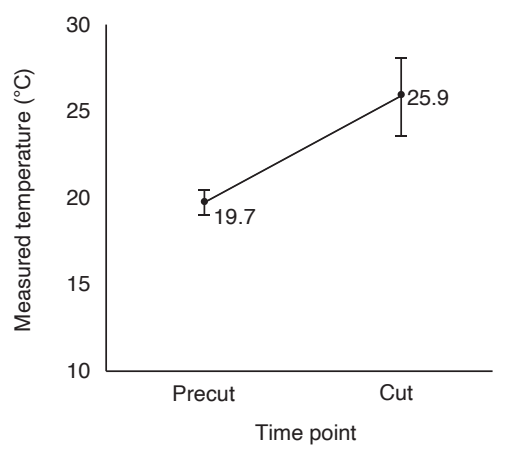

Temperature measure

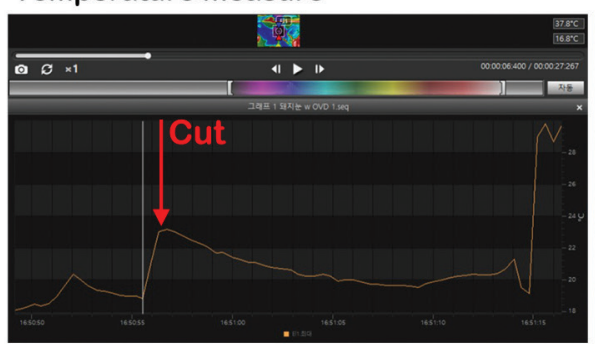

Temperature profile (cut)

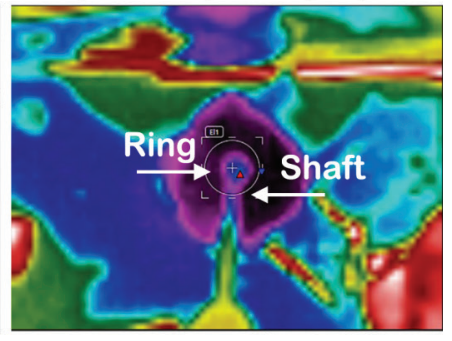

Fig. 5. Temperature change during thermal capsulotomy in porcine eye with or without an ophthalmic viscosurgical device (OVD). (A) For the top side measurements in porcine eyes without OVDs, the mean temperature rise was $10.5^{\circ} \mathrm{C} \pm 3.3^{\circ} \mathrm{C}$ and the mean peak temperature was $28.7^{\circ} \mathrm{C} \pm 3.4^{\circ} \mathrm{C}$. (B) For the top side measurements in porcine eyes with OVDs, the mean temperature rise was $6.2^{\circ} \mathrm{C} \pm 1.6^{\circ} \mathrm{C}$ and the mean peak temperature was $25.9^{\circ} \mathrm{C} \pm 2.3^{\circ} \mathrm{C}$.

ring. In comparison to previous animal studies, the results from the thermal detection device differed from the present study. An animal study used thermocouple temperature measurements, and our study used an infrared thermographer to evaluate detailed thermal changes. Therefore, it is difficult to objectively compare the results of the two studies. However, Innocenti et al. [21] compared the difference in the measured temperature between a thermal camera and thermocouple during phacoemulsification and found that the difference between the two devices was only an average of $0.5^{\circ} \mathrm{C}$. From our measurements, the temperature profiles of the naïve nitinol ring were inconceivably higher than those of previous animal studies $\left(109.0^{\circ} \mathrm{C} \pm 22.9^{\circ} \mathrm{C}\right)$.

In our previous study, cataract surgery using Zepto PPC caused minimal endothelial cell loss compared to conventional cataract surgery [15]. We hypothesized that an approximately $2^{\circ} \mathrm{C}$ to $6^{\circ} \mathrm{C}$ temperature elevation with a transient moment of approximately 3 to 6 seconds is not sufficient to influence the endothelium. Furthermore, in an in vitro study, the Zepto nitinol ring temperature elevation during contact with the Zepto nitinol ring on the porcine lens was much lower than that in the naïve status. This may have been due to effects from the media, such as the aqueous humor, anterior capsule, or particularly the OVD, which blocks and buffers the overheat damage from the corneal endothelium. When comparing the presence of the OVD in the cutting procedure, the OVD group's mean temperature elevation was much lower and their elevation time longer than in the non-OVD group (Fig. 5). Previous in vitro studies of porcine eyes showed that during ultrasound oscillation, especially torsional vibration in phacoemulsification, there was little corneal endothelium temperature elevation in the OVD group compared to the balanced salt solution group [22]. Therefore, it is estimated that the temperature rise of the Zepto PPC will have a negligible effect on the intraocular tissue in a general cataract surgery environment.

A limitation of this study is that we did not use a thermal 
probe; therefore, we could not assess the anterior chamber or endothelium temperature. The thermal profiles were set using an infrared thermographer; therefore, in the in vivo study, the available temperature values were the corneal surface and corneal incision around the Zepto handpiece. In the case of the corneal surface, the essential temperature change was not clear due to irrigation of balanced salt solution and structures below the corneal surface (cornea, anterior chamber, and OVD). Therefore, measuring the temperature of the Zepto handpiece was the best way to assess the temperature change of the Zepto nitinol ring. However, in the in vitro study, since we removed the central 8.0-mm-diameter porcine cornea, we could assess the temperature change of the nitinol ring directly. From these results, we can predict the endothelial temperature indirectly.

In conclusion, our results suggest that the Zepto PPC nitinol ring itself could induce an extremely high thermal rise of approximately $100^{\circ} \mathrm{C}$ for capsulotomy during the cutting procedure. However, in the in vivo study, the temperature difference was minimal. In the actual use of this device, there are several surrounding tissues and buffers, including the anterior capsule, anterior chamber, and the OVD around the nitinol ring, that could prevent extreme temperature rises and alleviate overheat damage to nearby intraocular tissues. The in vitro analysis showed that the OVD offered excellent buffering effects by blocking the thermal energy. This would protect the corneal endothelium and cut edge of the anterior capsule from the risk of endothelial cell loss and capsular phimosis.

\section{Conflict of Interest}

No potential conflict of interest relevant to this article was reported.

\section{References}

1. Gimbel HV, Neuhann T. Continuous curvilinear capsulorhexis. J Cataract Refract Surg 1991;17:110-1.

2. Bang SP, Yoo YS, Jun JH, Joo CK. Effects of residual anterior lens epithelial cell removal on axial position of intraocular lens after cataract surgery. J Ophthalmol 2018;2018:9704892.

3. Sanders DR, Higginbotham RW, Opatowsky IE, Confino J.
Hyperopic shift in refraction associated with implantation of the single-piece Collamer intraocular lens. J Cataract Refract Surg 2006;32:2110-2.

4. Walkow T, Anders N, Pham DT, Wollensak J. Causes of severe decentration and subluxation of intraocular lenses. Graefes Arch Clin Exp Ophthalmol 1998;236:9-12.

5. Aykan U, Bilge AH, Karadayi K, Akin T. The effect of capsulorhexis size on development of posterior capsule opacification: small (4.5 to $5.0 \mathrm{~mm}$ ) versus large (6.0 to 7.0 mm). Eur J Ophthalmol 2003;13:541-5.

6. Ravalico G, Tognetto D, Palomba M, et al. Capsulorhexis size and posterior capsule opacification. J Cataract Refract Surg 1996;22:98-103.

7. Hollick EJ, Spalton DJ, Meacock WR. The effect of capsulorhexis size on posterior capsular opacification: one-year results of a randomized prospective trial. Am J Ophthalmol 1999;128:271-9.

8. Nagy ZZ, Kranitz K, Takacs AI, et al. Comparison of intraocular lens decentration parameters after femtosecond and manual capsulotomies. J Refract Surg 2011;27:564-9.

9. Kranitz K, Takacs A, Mihaltz K, et al. Femtosecond laser capsulotomy and manual continuous curvilinear capsulorrhexis parameters and their effects on intraocular lens centration. J Refract Surg 2011;27:558-63.

10. Friedman NJ, Palanker DV, Schuele G, et al. Femtosecond laser capsulotomy. J Cataract Refract Surg 2011;37:1189-98.

11. Mastropasqua L, Toto L, Mattei PA, et al. Optical coherence tomography and 3-dimensional confocal structured imaging system-guided femtosecond laser capsulotomy versus manual continuous curvilinear capsulorhexis. $J$ Cataract Refract Surg 2014;40:2035-43.

12. Nagy Z, Takacs A, Filkorn T, Sarayba M. Initial clinical evaluation of an intraocular femtosecond laser in cataract surgery. J Refract Surg 2009;25:1053-60.

13. Donaldson KE, Braga-Mele R, Cabot F, et al. Femtosecond laser-assisted cataract surgery. J Cataract Refract Surg 2013;39:1753-63.

14. Chang DF, Mamalis N, Werner L. Precision pulse capsulotomy: preclinical safety and performance of a new capsulotomy technology. Ophthalmology 2016;123:255-64.

15. Bang SP, Jun JH. Comparison of postoperative axial stability of intraocular lens and capsulotomy parameters between precision pulse capsulotomy and continuous curvilinear capsulotomy: a prospective cohort study. Medicine (Baltimore) 2019;98:e18224.

16. Waltz K, Thompson VM, Quesada G. Precision pulse cap- 
sulotomy: initial clinical experience in simple and challenging cataract surgery cases. J Cataract Refract Surg 2017;43:606-14.

17. Kelkar JA, Mehta HM, Kelkar AS, et al. Precision pulse capsulotomy in phacoemulsification: clinical experience in Indian eyes. Indian J Ophthalmol 2018;66:1272-7.

18. Hooshmand J, Abell RG, Allen P, Vote BJ. Thermal capsulotomy: initial clinical experience, intraoperative performance, safety, and early postoperative outcomes of precision pulse capsulotomy technology. J Cataract Refract Surg 2018;44:355-61.

19. Thompson VM, Berdahl JP, Solano JM, Chang DF. Comparison of manual, femtosecond laser, and precision pulse capsulotomy edge tear strength in paired human cadaver eyes. Ophthalmology 2016;123:265-74.

20. Chylack LT Jr, Wolfe JK, Singer DM, et al. The lens opacities classification system III. The Longitudinal Study of Cataract Study Group. Arch Ophthalmol 1993;111:831-6.

21. Innocenti B, Diciotti S, Bocchi L, et al. A comparison between internal and surface temperature measurement techniques during phacoemulsification cataract surgery: thermocamera versus thermocouple. J Appl Biomater Biomech 2008;6:151-6.

22. Suzuki H, Igarashi T, Shiwa T, Takahashi H. Efficacy of ophthalmic viscosurgical devices in preventing temperature rise at the corneal endothelium during phacoemulsification. Curr Eye Res 2016;41:1548-52. 